\title{
Educação e Pandemia: Um estudo complexo sobre o Regime Especial de Ensino implantado no município de Patos no Estado da Paraíba, Brasil.
}

\author{
Education and Pandemics: A complex study about special education regime \\ implemented in the county of Patos in the state of Paraíba.
}

Juana Thaynar de Souza Oliveira ${ }^{1 *}$, Elzenir Pereira de Oliveira ${ }^{1},{ }^{2}$, Erich de Freitas Mariano ${ }^{1}$, Janine Vicente Dias ${ }^{3},{ }^{4}$, Mariana Andrade Medeiros ${ }^{1}$, Jair Moisés de Sousa ${ }^{1}$

\begin{abstract}
RESUMO
Em decorrência da pandemia causada pelo novo coronavírus, municípios, estados e o governo federal foram forçados a suspender as aulas presenciais. A Secretaria de Estado da Educação e da Ciência e Tecnologia (SEECT) do Governo da Paraíba, por meio da Portaria No 418, de 17 de abril de 2020, instituiu o Regime Especial de Ensino (REE). A nova situação levantou muitos questionamentos, e, consequentemente, um contexto social de desigualdades presentes em nossa sociedade. A pesquisa se deu a partir da aplicação de um questionário com os professores da rede estadual de ensino da Paraíba e teve como objetivo compreender os desafios vivenciados nesse momento. Os dados foram analisados com base nos fundamentos do pensamento complexo. Conclui-se que, a pandemia trouxe a necessidade dos professores se adaptarem ao uso de plataformas que, até então, não faziam parte de suas vidas, com isso sentimentos de medo e ansiedade tomaram de conta dos docentes e estudantes, além da falta de equipamentos para a realização virtual das atividades acadêmicas. Os professores demonstraram conhecimentos sobre as TICs, embora não tenham total domínio da utilização das mesmas. Por fim, a crise enfrentada pela educação e seus impactos são incertos, emergindo a necessidade de reformas no nosso atual modelo de ensino.
\end{abstract}

Palavras-chave: Educação; Pandemia; Ensino remoto;

\begin{abstract}
As a result of the pandemic caused by the new coronavirus, counties, states and the federal government were forced to cancel in-person classes. The State Secretariat for Education and Science and Technology (SEECT) of the Government of Paraíba, through Ordinance No. 418, of April 17, 2020, instituted the Special Education Regime (REE). The new situation raised many questions, taking into account the social context of inequalities present in our society. From the application of a questionnaire with teachers from the state education system in Paraíba, we sought to understand the challenges experienced at that time. Their answers were analyzed with foundations of complex thinking. It is concluded that the pandemic brought the need for teachers to adapt to the use of platforms that until then were not part of their lives, with that feelings of fear and anxiety took over the teachers and their students, in addition to the lack of equipment for both. Teachers demonstrated knowledge about ICTs, although they do not have complete
\end{abstract}

\footnotetext{
${ }^{1}$ Universidade Federal de Campina Grande, Patos, PB. *E-mail: juanathaynar7@gmail.com

${ }^{2}$ Faculdades Integradas de Patos, Patos, PB.

${ }^{3}$ Universidade Estadual da Paraíba, Patos, PB.

${ }^{4}$ Secretaria de Educação e da Ciência e tecnologia, Patos, PB.
} 
mastery of their use. The crisis faced by education and its impacts are uncertain, with the need for reforms in our current teaching model emerging.

Keywords: Education; Pandemic; Special Education Regime.

\section{INTRODUÇÃO}

A pandemia causada pelo novo coronavirus (SARS - CoV-2), levou municípios, estados e o governo federal a suspenderem as aulas presenciais, tanto na rede pública quanto privada. A Secretaria de Estado da Educação e da Ciência e Tecnologia (SEECT) do Governo da Paraíba, por meio da Portaria $N^{\circ} 418$, de 17 de abril de 2020, instituiu o Regime Especial de Ensino (REE).

Ao ser implantado em toda a rede pública estadual, o REE trouxe a substituição das aulas presenciais por aulas remotas em plataformas digitais e nesse processo, os professores foram submetidos a um curso de formação que visou capacitá-los no uso das tecnologias educacionais digitais.

Esta nova situação educacional levanta então questionamentos em inúmeros sentidos de alta complexidade, principalmente com relação às estruturas de acesso à rede banda larga e equipamentos tecnológicos. Questões relacionadas ao contexto social de desigualdade também devem ser levados em conta. O nível de conhecimento dos professores no uso das plataformas, que passaram a fazer parte de suas rotinas diárias, além do nível de preparo dos docentes antes e depois da capacitação, oferecida às pressas em decorrência da urgência da situação totalmente atípica, precisa ser discutido. Há necessidade de uma verificação da eficiência do processo de transição para a nova interação com as tecnologias de comunicação.

Em meio ao contexto social emergencial, a educação é uma área que merece atenção. Tendo em vista todas as tensões enfrentadas no Brasil e no mundo, tais como o medo da pandemia e outros distúrbios psicológicos, além do agravamento das desigualdades sociais, faz pensar na educação como uma necessidade, uma vez que o foco deve ser na aprendizagem do aluno e nos instrumentos de ensino construídos pelo professor. (PASINI; CARVALHO; ALMEIDA, 2020).

O modelo de educação atual já mostrava graves rupturas e o atual contexto evidenciou ainda mais sua fragilidade. A educação brasileira enfrentou desafios, há 
décadas que os pesuisadores já questionavam o modelo de educação, como por exemplo Paulo Freire (1996) e Edgar Morin (2000). O modelo educacional vigente já apresentava falhas e eram discutidas as formas de reprodução da educação bancária, criticada por Freire, e o padrão de ensino focado na "cabeça cheia". As problemáticas desse modelo vão desde estrutura de aulas aos processos avaliativos empregados, e se tornaram ainda mais agravantes no modelo de ensino emergencial a distância. Para Santana \& Sales (2020, p. 77 apud 2020, KENSKI, 2020; SANTANA, 2019) “a educação na contemporaneidade ainda permanece com o desafio de educar estudantes do século XXI, com professores do século XX e escolas do século XIX”.

Neste sentido, Freire (1996) cita que o ser humano é um ser consciente de sua presença no mundo e com seu poder criador, é imprescindível a tomada de consciência de que novos temos exigem novas práticas de ensino. Em seu trabalho, Bruno \& Morais (2006) vão dizer que, como educadores, precisamos nos atualizar e reconhecer as mudanças vivenciadas mediante aos avanços no contexto de mundo (SILVA; SANTOS, 2006). Desta forma, as Tecnologias da informação e comunicação (TICs) são uma realidade há muito tempo no mundo e faz-se necessário sua implementação da melhor forma no âmbito educacional. Para muitos docentes, essa ferramenta da educação ainda era uma realidade que estava engatinhando, entretanto, uma situação abrupta tornou-nos dependentes do uso dessas TICs.

O trabalho em questão, tem como objetivo compreender a concepção de professores sobre o REE e sua consequente ação pedagógica, mediante compreensão das experiências docentes.

\section{METODOLOGIA (OU MATERIAS E MÉTODOS)}

Este trabalho possui natureza qualitativa teórico-conjectural com formulação e aplicação de um questionário que foi aplicado aos professores da rede estadual de ensino do município de Patos, no estado da Paraíba, de maneira remota respeitando todos os protocolos de saúde. As informações levantadas foram analisadas, tendo como suporte e eixo norteador os paradigmas que compõem o pensamento das Ciências da Complexidade de Edgar Morin (2000) e a Pedagogia de Paulo Freire (1996). 
Desse modo, além de Edgar Morin, autores como Basarab Nicolescu, Gaston Bachelard (1996), Edgard de Carvalho e Maria da Conceição (2012) compõem o núcleo básico de suporte teórico das Ciências da Complexidade. Logicamente, as ideais do próprio Paulo Freire são os fundamentos guias da pedagogia freireana.

O instrumento metodológico escolhido para a construção do cenário fenomenológico, ao qual se propõe a pesquisa em questão, é o questionário. Por possuir em sua natureza a possibilidade de abarcar, tanto questões subjetivas como objetivas, na qual o entrevistado pode expressar suas ideias de forma livre, bem como a possibilidade de requerer do pesquisador concepções fechadas sobre um determinado tema, entendemos que tal método é o mais apropriado para alcançar os objetivos da pesquisa (MATOS, 2002).

O questionário contemplou tanto questões objetivas quanto subjetivas e foi dividido em três partes. A primeira parte envolveu questões formativo-pedagógicas como: formação acadêmica, tempo de conclusão do curso e atuação docente e se leciona sua disciplina de formação. A segunda parte abordou a concepção dos professores sobre: formação docente, tecnologias educacionais digitais, desafios da educação contemporânea, satisfação com a carreira docente, conhecimentos técnicos científicos sobre o Covid-19, bem como a concepção sobre os impactos sociais da referida pandemia. A terceira parte relacinou as concepções e avaliações dos professores sobre a implantação, utilização e consequências do Regime Especial de Ensino.

Conforme a declaração de pandemia do coronavírus pela Organização Mundial de Saúde, de 11 de março de 2020, assim como a Instrução normativa N²1, de 2 de março de 2020, do Ministério da Economia e as portarias GR/UFCG 28, de 18 de março de 2020 e PRPG/GPR No003, de 18 de março de 2020, as entrevistas foram realizadas mediante uso de plataformas digitais, além do Whatsapp, e-mail ou chamada telefônica.

\section{DESENVOLVIMENTO}

Após a aprovação do comitê de ética do Centro Universitário de Patos, entrou-se em primeiro momento em contato com os responsáveis das duas escolas estaduais escolhidas do município de Patos na Paraíba. Posteriormente, entramos em contato com 
os professores das escolas para que os que se sentissem dispostos a contribuir com a pesquisa respondessem o questionário que lhes seria enviado, via Link, de maneira remota, através da plataforma Google Forms. Foram obtidas respostas de 35 professores durante o mês de abril de 2021. O questionário era composto por questões objetivas e subjetivas, os resultados obtidos foram analisados com base no pensamento complexo e serão expostos e discutidos nos tópicos seguintes.

\section{RESULTADOS E DISCUSSÃO}

\section{Perfil dos docentes.}

Os professores participantes da pesquisa são todos funcionários da rede estadual de ensino do estado da Paraíba do município de Patos, com relação a idade $27,7 \%$ possuem entre 20 e 30 anos, $65,7 \%$ tem entre 40 e 50 anos de idade e os que possuem 60 anos ou mais corresponde a apenas $8,6 \%$.

O estudo mostra que a faixa etária dos profissionais brasileiros, encontra-se entre 40 e 50 anos, o que alguns autores vão chamar de Geração X, a qual não nasceu na era da tecnologia e teve de aprender a lidar com a mesma após a década de 1980. (BARBOSA et al. 2020, p. 261 apud MORAES, 2011, p. 20).

Sobre o tempo de exercício da profissão, os participantes que possuem mais de 21 anos de profissão representam 54,3\%, entre 16 e 20 anos de profissão 8,6\%, de 6 a 15 anos $34,3 \%$ e os que têm entre 1 e 5 anos representaram apenas 2,9\%. Observou-se que metade desses docentes possuem 21 anos ou mais de exercício da profissão, sendo então profissionais experientes com mais de 2 décadas em sala de aula.

Gráfico 1 - Tempo de exercício da profissão. 


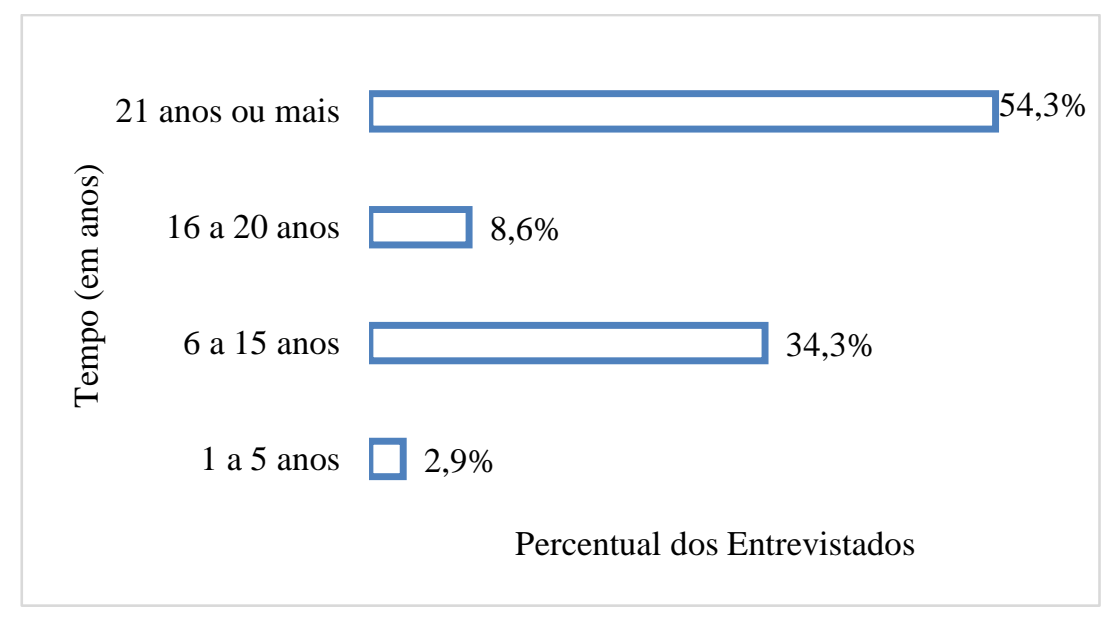

Fonte: Autores, 2021.

Em relação aos anos de formação ocorreu uma grande variação, entre os anos de 1983 e 2017.

Os professores são formados em variados cursos de graduação, contemplando todas as disciplinas da rede básica de ensino, e a maioria, 97,1\% deles afirmaram que lecionam sua disciplina de formação, contra 2,9\% que responderam que não leciona sua disciplina de formação acadêmica.

Com relação ao seu vínculo empregatício com as escolas, $80 \%$ deles afirmaram serem funcionários efetivos e $20 \%$ dos professores disseram ser contratados. Os entrevistados variam entre homens e mulheres, sendo $68,6 \%$ deles do gênero feminino e $31,4 \%$ do gênero masculino.

Com relação ao grau de formação mais alto, foi constatado na pesquisa que, $80 \%$ deles possuíam especialização, $11,4 \%$ são mestres e apenas $8,6 \%$, são graduados, não tendo no quadro docente nenhum doutor. No gráfico 3 é possivel observar os percentuais

Gráfico 2 - Maior grau de titulação dos docentes. 


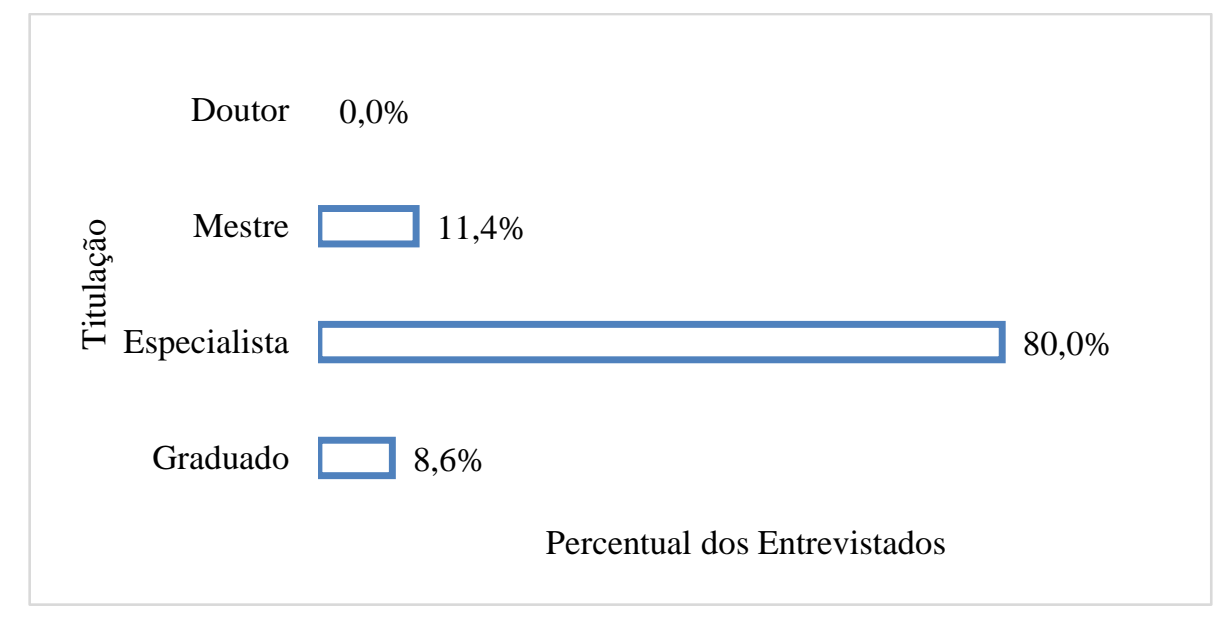

Fonte: Autores, 2021.

Os dados da pesquisa são compatíveis com as informações do Censo de Educação Básica da Paraíba de 2019 do Instituto Nacional de Estudos e Pesquisa Anísio Teixeira (INEP, 2019) em que 95,2\% dos 11.247 professores que atuam na rede estadual de ensino no nível médio no estado da Paraíba, têm nível superior completo. Já com relação aos anos de formação desses profissionais ocorreu uma grande variação entre os anos de 1983 e 2017.

Sendo assim, podemos traçar o perfil desses docentes como homens e mulheres, em maioria de meia idade, fazendo parte da geração $X$ que é o perfil dos educadores brasileiros em geral.

\section{Concepções dos docentes sobre as tecnologias educacionais - TICs e o seu uso.}

Com relação aos entendimentos dos docentes sobre suas concepções sobre as TICs, a maioria dos professores demonstraram entendimento sobre o termo. Podemos destacar algumas respostas dadas pelos entrevistados, em que definiram as TICs como "são tecnologias digitais da informação e comunicação que sejam incorporadas para auxiliarem no processo de ensino aprendizagem." e "Tecnologias são inovações que auxiliam de alguma forma o ser humano e as educacionais são as tecnologias utilizadas para princípios educativos.".

Nas respostas, observou-se um bom entendimento dos conceitos, os quais já existem hà bastante tempo, embora não fosse algo tão empregado na realidade de ensino desses docentes. Para Soares-Leite (2012 p.175) ' 'inserir na educação essas TICs pode 
ser uma ferramenta com muito potencial em contribuir positivamente para a melhoria do processo de ensino-aprendizagem.", apesar da situação emergente exigir uma rápida adaptação e não ser a situação ideal, muito já se defende a utilização das TICs como importantes ferramentas no processo de ensino aprendizagem.

Com relação a utilização das plataformas de ensino, os docentes afirmaram utilizar variados aparelhos tecnológicos de acesso as redes, em que notebooks e smartphones lideram o uso, até o momento da pesquisa não havia ocorrido incentivo de parte do governo para a compra de equipamentos tecnológicos para esses professores.

O curso de formação oferecido pela SEETC, objetivou capacitar esses profissionais para a utilização das plataformas e uso das TICs no REE, dos participantes da pesquisa 94,3\% dos docentes afirmaram que participaram desta formação e apenas $5,7 \%$ não participaram.

Gráfico 3 - Participação no curso de qualificação oferecido pela SEETC.

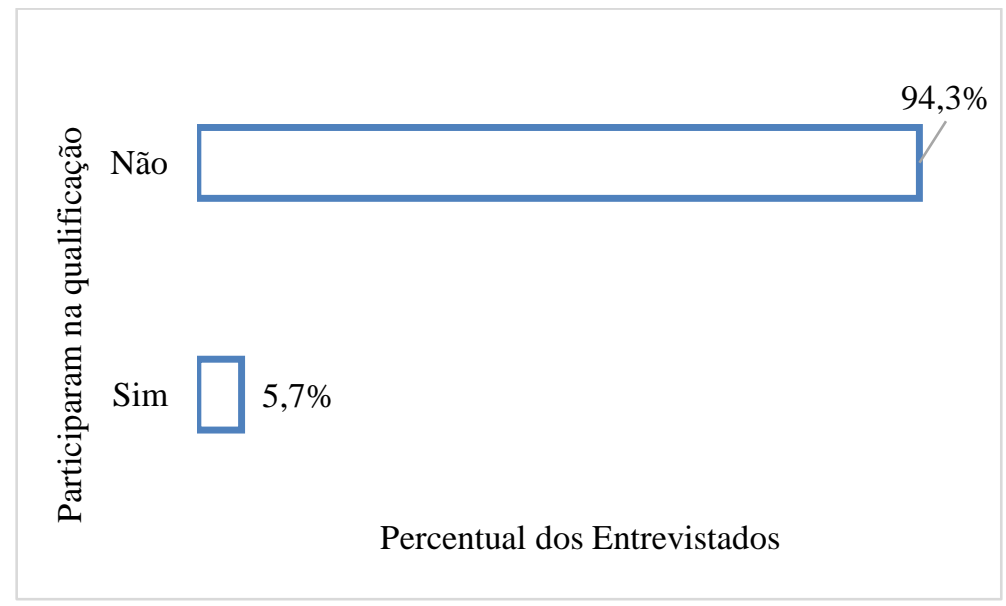

Fonte: Autores, 2021.

Quando questionados se já haviam participado em outros momentos de cursos de qualificação anteriores ao REE 51,4\% afirmaram que sim e 48,6\% responderam que não haviam participado.

A respeito do curso de qualificação oferecido pelo SEECT e se o tempo do curso foi suficiente para prepará-los, obteu-se que 71,4\% julgaram o tempo insuficiente enquanto que 28,6\% afirmaram ter sido suficiente, como exposto no gráfico 6 . 
Gráfico 4 - Se foi suficiente o tempo do curso de qualificação oferecido.

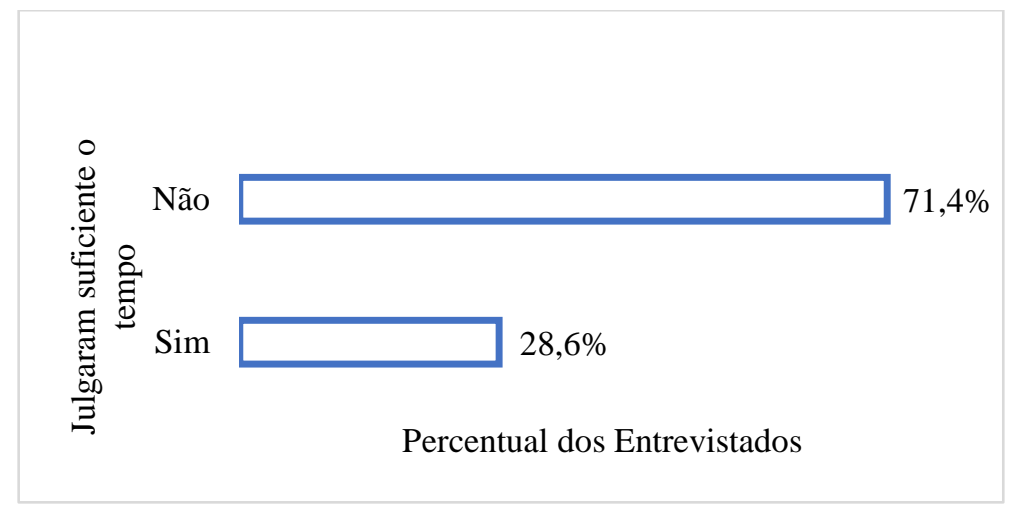

Fonte: Autores, 2021.

Educar é um processo mútuo, onde quem ensina aprende ao ensinar e quem aprende ensina ao aprender, sendo assim para que aja real aprendizagem faz-se necessário a presença de professores e alunos e ao longo da história a humanidade como seres sociais que são perceberam que era possível trabalhar maneiras, caminhos, métodos de ensinar (FREIRE, 1996).

A educação brasileira engatinhava a lentos passos para introduzir em suas práticas de ensino modelos que não compreendessem ao aluno e o professor dentro de uma sala de aula, muitos são os desafios para as implementações dessas: limitações tecnológicas, práticas e metodologias, resistências muitas das vezes dos professores por despreparo em suas formações ou até mesmo por medo, entre tantas outras. Santana (2020), afirma que a "pandemia da COVID-19 evidencia as fragilidades da educação e, ao mesmo tempo, expõe indicativos de transformação necessária nos modos de ensinar e aprender no século XXI" (SANTANA, 2020, p.88).

Para Morin (2000), “o futuro permanece aberto e imprevisível” (MORIN, 2000, p.79), o mundo nunca foi e nem nunca será estático, sendo assim faz-se necessário termos consciência de que o inesperado está sempre a nossa espreita e que a desordem faz parte da ordem e vice versa.

Os educadores da rede estadual de ensino da Paraíba em seus relatos a respeito de como tem sido esses momentos relataram sentimentos diversos, além de muitos desafios que o momento inesperado de pandemia nos colocou. No gráfico abaixo é possível ver os resultados das respostas, deve-se levar em conta que era possível marcar mais de uma alternativa. 
Gráfico 5 - Sentimentos relatados pelos docentes.

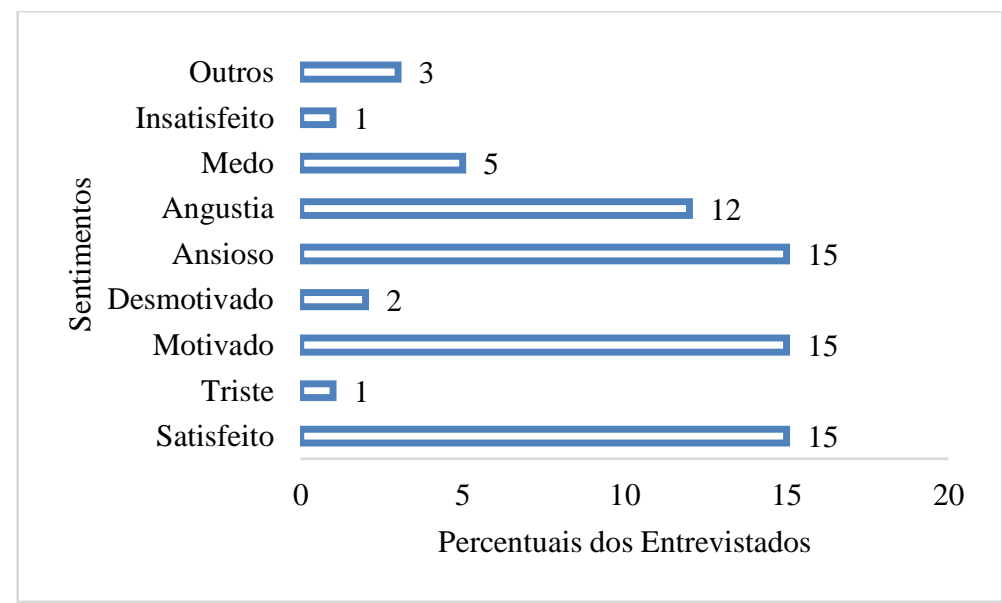

Fonte: Autores, 2021.

Os professores relataram em maioria um misto de sentimentos que momentos de incerteza trazem à tona, dentre eles medo, angústia e ansiedade destacam-se, isso pode ser explicado pela situação de medo e caos gerados pela situação mundial, além do acarretamento do despreparo para lidar com a situação, apesar disso muitos professores também se consideraram satisfeitos e motivados em suas aulas.

Morin (2000), acredita que a educação do futuro precisa aprender a lidar com o inesperado, em suas palavras:

\footnotetext{
"É preciso aprender a enfrentar a incerteza, já que vivemos em uma época de mudanças em que os valores são ambivalentes, em que tudo é ligado. É por isso que a educação do futuro deve se voltar para as incertezas ligadas ao conhecimento." (MORIN, 2000, p.84)
}

Com relação aos desafios, os professores relataram em maioria as limitações tecnológicas e de acesso a rede de sua parte e de seus alunos, a ausência dessas ferramentas que vão ser parte fundamental para implementação do REE, a ausência dessas ferramentas básicas para a manutenção do ensino remoto, dificulta ainda mais chegar ao objetivo final desses educadores para com seus alunos, Freire afirma que: 
sua tarefa docente. Para isso, precisa de condições favoráveis, higiênicas, espaciais, estéticas, sem as quais se move menos eficazmente no espaço pedagógico." $(1996$, p.27)

Partindo deste pensamento de Freire (1996), os docentes precisam ter as condições necessárias para fazer seu trabalho e na pandemia os computadores e smartphones passaram a ser equipamentos essenciais para a realização destas aulas não presenciais. Materiais esses os quais os professores entrevistados relataram, muito recorrentemente a sua ausência, o acesso a uma boa internet e a bons computadores, além disso o despreparo em suas formações acadêmicas para utilização dessas tecnologias.

A pesquisa demonstrou que, muitos professores reclamaram também de solidão em suas aulas e falta de participação dos alunos. Outro ponto relevante, foi a preocupação com a evasão escolar recorrente, $31,4 \%$ dos docentes afirmaram ter observado isso, a razão desta evasão pode ser motivado pela mudança de paradigma e pela ausência de meios tecnológicos para os mesmos, segundo os relatos dos entrevistados. No trabalho citado anteriormente por Barbosa (2020) obteve-se uma alta taxa de 59\% de diminuição da presença e participação dos alunos nas aulas. (BARBOSA; VIEGAS; BATISTA, 2020, p. 273).

\section{CONCLUSÃO}

A pandemia de Covid-19 expôs ao mundo fragilidades em todas as esferas existentes, a situação educacional em questão precisou adequar-se à urgência do momento e por sua vez no estado da Paraíba institui-se o regime especial de ensino. Em um curto espaço de tempo, os professores precisaram adaptar-se ao uso de plataformas, que em sua maioria, não faziam parte de suas vidas. Com isso, sentimentos de medo, ansiedade e temor tomam de conta desses docentes e de seus estudantes, sentimentos esses, agravados pela crise de saúde pública em que o mundo se encontra.

Muitas foram as limitações tecnológicas e de capacitação que esses docentes relataram vivenciar, sendo assim a crise enfrentada pela educação, demonstra que ainda se é necessário preparo para momentos como esse. Os efeitos e as projeções do impacto 
causado na educação dos brasileiros, toma proporções desconhecidas e incertas, o que demonstra ainda, a necessidade de reformas no nosso modelo de ensino. A respeito do uso das TICs os professores da Rede estadual da Paraíba demonstraram compreender a conceituação dos termos, entretanto, ainda se faz tímido e dificultoso colocá-las em prática, o que os deixam temerosos. Faz-se necessário, maior investimento em capacitação nessa área, ficando,além disso, evidente as limitações em equipamentos desses docentes e também de seus alunos, causando um grau de exclusão ao qual os impactos são desconhecidos. E sem dúvidas, esse momento na nossa história deixará impactos, sejam eles negativos ou positivos, dos quais não se tem projeções até o momento.

\section{REFERÊNCIAS}

ALMEIDA, Maria da Conceição. Ciências da complexidade e educação: razão apaixonante e politização do pensamento. Natal: Editora da UFRN, 2012.

BACHELARD, Gaston. A formação do espírito cientifico. Rio de Janeiro: Contraponto Editora, 1996.

BARBOSA, André Machado; VIEGAS, Marco Antonio Serra; BATISTA, Regina Lucia Napolitano Felício Felix. Aulas presenciais em tempos de pandemia: relatos de experiências de professores do nível superior sobre as aulas remotas. Revista Augustus, v. 25 (51): 255-280, 2020. Acesso em: 28 de junho de 2020. Disponível em: https://revistas.unisuam.edu.br/index.php/revistaaugustus/article/view/565/302.

ESTADO DA PARAÍBA. Portaria No 418 de 17 de abril de 2020 da Secretaria de Estado da Educação e da Ciência e Tecnologia (SEECT), dispõe sobre a adoção, no âmbito da rede pública estadual de ensino da Paraíba, do regime especial de ensino, como medida preventiva à disseminação do COVID-19, e dá outras providências. Acesso em 27 de junho de 2020. Disponível em https://paraiba.pb.gov.br/diretas/secretaria-da-educacaoe-da-ciencia-e-tecnologia/noticias/secretaria-de-educacao-anuncia-regime-especial-deensino-da-rede-estadual-durante-pandemia-do-novo-coronavirus.

FREIRE, Paulo. Pedagogia da Autonomia. 25ª Ed. São Paulo: Paz e Terra, 1996. 
GATTI, Bernadete. A formação de professores no Brasil: características e problemas. Educação \& Sociedade. v 31 (113): 1355-1379, 2010. Acesso em 28 de junho de 2020. Disponível em: https://www.scielo.br/pdf/es/v31n113/16.

CARVALHO, Ana Maria Pessoa de; GIL-PEREZ, Daniel. Formação de professores de ciências: tendências e inovações. 10a Ed. São Paulo:Cortez editora, 2011.

HEISENBERG, Werner. A ordenação da realidade. Rio de Janeiro: Editora Sulina, 2009.

Instituto Nacional de Estudos e Pesquisas Educacionais Anísio Teixeira.Resumo Técnico: Censo da Educação Básica Estadual 2019 [recurso eletrônico].- Brasília: Instituto Nacional de Estudos e Pesquisas Educacionais AnísioTeixeira, 2020. xx p. : il. Acesso em: 01 de julho de 2021. Disponível em: https://download.inep.gov.br/publicacoes/institucionais/estatisticas_e_indicadores/resu mo_tecnico_do_estado_da_paraiba_censo_da_educacao_basica_2019.pdf

MATOS, Kelma Socorro Lopes de. Pesquisa educacional: o prazer de conhecer. $2^{\text {a }}$ Ed. Fortaleza: Edições Demócrito Rocha, 2002.

MORIN, Edgar. Introdução a pensamento complexo. $4^{\mathrm{a}}$ edição. Porto Alegre, Editora Sulina, 2000.

PASINI, Carlos Giovani Delevati; CARVALHO, Élvio de; ALMEIDA, Lucy Hellen Coutinho. A educação híbrida em tempos de pandemia: Algumas considerações. Observatório Socioeconômico da COVID-19. Acesso em: 29 fevereiro de 2021. Disponível em: https://www.ufsm.br/app/uploads/sites/820/2020/06/Textos-paraDiscussao-09-Educacao-Hibrida-em-Tempos-de-Pandemia.pdf

SANTANA, Camila Lima Santana; SALES, Katia Marise Borges. Aula em casa: educação, tecnologias digitais e pandemia covid-19. Interfaces Científicas. v. 10 (1): 75-92, 2020. DOI 10.17564/2316-3828.2020v10n1p75-92. Disponível em: https://periodicos.set.edu.br/educacao/issue/view/339. Acesso em: 7 de março de 2021.

SILVA, Marco; SANTOS, Edméa. Avaliação da aprendizagem em educação online. $2^{a}$ edição. São Paulo: Loyola, 2006. 
A cabeça bem feita. $8^{\text {a }}$ Ed. Rio de Janeiro: Bertrand Brasil, 2003a.

A necessidade de um pensamento complexo. In: Mendes, Candido (org). Representação e complexidade. Rio de Janeiro: Garamond Editora, $2003 b$.

Introdução ao pensamento complexo. Porto Alegre: Editora Sulina,

2005.

Educação e complexidade: os sete saberes e outros ensaios. In: Almeida, Maria da Conceição de; Carvalho, Edgard de Assis (orgs.). $6^{a}$ Ed. São Paulo: Cortez Editora, 2013.

TARDIF, Maurice. Saberes docentes e formação profissional. Petrópolis: Vozes, 2002.

Recebido em: 01/12/2021

Aprovado em: 21/12/2021

Publicado em: 30/12/2021 